\title{
Reliability of the Estimation of the Take of Split Thickness Graft by the Observation Method
}

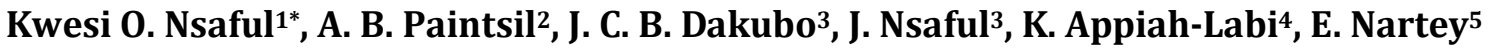 \\ ${ }^{1}$ Plastic, Reconstructive Surgery and Burns Unit, 37 Military Hospital, Accra, Ghana \\ ${ }^{2}$ National Reconstructive Plastic Surgery and Burns Unit, Korle Bu Teaching Hospital, Accra, Ghana \\ ${ }^{3}$ The Surgical Department, Korle Bu Teaching Hospital, Accra, Ghana \\ ${ }^{4}$ Department of Microbiology, Korle Bu Teaching Hospital, Accra, Ghana \\ ${ }^{5}$ Data and Statistical Analysis Department, Korle Bu Teaching Hospital, Accra, Ghana \\ Email: ^knsaful@yahoo.co.uk
}

How to cite this paper: Nsaful, K.O., Paintsil, A.B., Dakubo, J.C.B., Nsaful, J., Appiah-Labi, K. and Nartey, E. (2020) Reliability of the Estimation of the Take of Split Thickness Graft by the Observation Method. Modern Plastic Surgery, 10, 62-74. https://doi.org/10.4236/mps.2020.103008

Received: April 24, 2020

Accepted: June 2, 2020

Published: June 5, 2020

Copyright $\odot 2020$ by author(s) and Scientific Research Publishing Inc. This work is licensed under the Creative Commons Attribution International License (CC BY 4.0).

http://creativecommons.org/licenses/by/4.0/ cc) (i) Open Access

\begin{abstract}
Introduction: Split thickness skin grafts are frequently employed to provide biological cover for extensive wounds. The take of the skin graft is traditionally estimated by observation and recorded as a percentage. The intent of this study was to ascertain the reliability of the observation method in comparison with the Image J digital programme. Materials and Methods: The study was a longitudinal study conducted on the wards of the National Reconstructive Plastic Surgery and Burns Centre (NRPSBC) at the Korle Bu Teaching Hospital (KBTH) on patients who were admitted during the period of the study with wounds who received split skin grafts. Image $\mathrm{J}^{\circledR}$, an image analysis program, was employed in the calculation of the take of the grafts. These were compared to values obtained by estimation by observation. Results: There was no statistically significant difference between the estimation of graft take, made by observation and using Image $\mathrm{J}^{\triangleright}$ digital programme. Conclusion: The estimation of graft take by observation is an acceptable practice.
\end{abstract}

\section{Keywords}

Split Skin Graft, Take of Graft, Estimation by Observation, Image J

\section{Introduction}

Skin grafts are commonly used to close skin defects and have been used since the early 1500s [1]. The practice originated among the tile maker caste in India approximately 3000 years ago [2].

A Split-Thickness Skin Graft (STSG) is indicated in most wounds that cannot be closed primarily or when closure by secondary intention is contraindicated. It 
is also indicated for a relatively large wound $(>5 \mathrm{~cm}$ in diameter) that would take many weeks to heal secondarily [3]. Skin grafts are employed in a variety of conditions, such as traumatic wounds, defects after tumour resection, burn reconstruction, scar contracture release, congenital skin deficiencies, hair restoration, vitiligo, and nipple-areola reconstruction [2] [4] [5].

The take of the skin graft is traditionally estimated by observation and recorded as a percentage-a take of $100 \%$ occurring when all the recipient wound bed is covered by the skin graft. However, very little work is available to ascertain the reliability of the estimation by observation method. This work aims at ascertaining the reliability of the observation method.

Image J is a Java-based program developed at the National Institutes of Health and the Laboratory for Optical and Computational Instrumentation (LOCI, University of Wisconsin) [6]. Image J known in previous incarnations as NIH Image, is a scientific image analysis program [7] [8] [9].

Image J can display, edit, analyze, process, save, and print 8-bit color and grayscale, 16-bit integer, and 32-bit floating point images [10]. Image J can be used to calculate area and pixel value statistics of user-defined selections and intensity-threshold objects. It can measure distances and angles. It can create density histograms and line profile plots [10].

The Image J method was employed in the calculation of the take of the grafts. These were compared to values obtained by estimation by observation.

\section{Methodology}

\subsection{Study Design}

The study was a longitudinal analytical study. The study was conducted on the wards of the NRPSBC at the KBTH.

The study was conducted on patients with burns and other ulcers, which required split-thickness grafting, brought to the NRPSBC at the KBTH for management. Patients with burn wounds and acute ulcers admitted to the NRPSBC at the KBTH during the period of the study who required split skin grafting as part of their treatment were included in the study. Excluded from the study were;

1) Patients with chronic ulcers-A chronic ulcer is a wound that shows no tendency to heal after three months of appropriate treatment or is still not fully healed at 12 months [11].

2) Weight bearing plantar ulcers.

3) Patients with previously failed skin grafts.

The period of the study spanned May 2016 to Jan 2017.

The sample size for the study was calculated comparing two proportions i.e. the proportion of graft failure due to infection and proportion of graft failure in general.

A total minimum sample of 65 was obtained. Accounting for contingencies such as loss to follow-up and incomplete data, the sample size was increased by 
$10 \%$ (minimum sample of 72 ).

The sample estimate for the study was therefore 72 patients.

Data collected included:

- Patient demographics,

- Ulcer aetiology,

- The Percentage graft take by observation,

- The Percentage graft take using the Image J.

Graft failure was defined as loss of split skin graft that will require re-grafting of the wound bed.

\subsection{Procedure}

Skin grafts were performed by standard operating techniques. All operations were performed under either general or regional anaesthesia with prophylactic antibiotics (Intravenous Cefuroxime-Child 1 month - 18 years: $50 \mathrm{mg} / \mathrm{kg}$, Adult: $1.5 \mathrm{gm})$. Split thickness skin grafts were harvested using a Graft knife or a Dermatome. To ensure as much as possible that the graft thickness was similar, in all cases:

1) During the use of Graft knife, the distance between the roller and the blade was kept constant with the wheel locked between calibrations 1 and 2 .

2) During the use of the Dermatome, it was set at calibration 0.10 inches.

The grafts, when required, were meshed prior to application. The grafts were secured to the wound beds with sutures or staples. In addition, immobilization techniques including the use of bolster dressings and Plaster of Paris were used when skin grafts were applied onto mobile surfaces. This was done to prevent movement of the graft on the bed, which will interrupt revascularization.

All patients for this study were placed on routinely used intravenous antibiotics Cefuroxime (Child 1 month to 18 years: $20 \mathrm{mg} / \mathrm{kg}$ every 8 hours, Adult: 750 mg every 8 hours). A dose was given intraoperatively and regular doses given postoperatively for 5 days and then on oral Cefuroxime (Child 3 months- 12 years: $30 \mathrm{mg} / \mathrm{kg} / \mathrm{day}$ suspension PO in 2 divided doses, or Adult: $500 \mathrm{mg} 12$ hourly) from POD 6 to POD 14.

The "take" of the graft was estimated by observation by any of three Senior Residents assigned to this study. These Senior Residents were blinded all through this study to the Image J results. This was done at the change of dressing of the recipient site i.e. Post-operative days 5, 10 and 14. The graft "take" on these days was recorded as a percentage.

\subsection{The Use of Image J ${ }^{\circledR}$ in Graft Take Measurements}

To measure the area of the wound covered by the graft as well as the raw area(s) (i.e. the area not covered by the graft) a known measure on the patient is taken and used to set the scale for the measurement. In Patient 04 on POD 5, for example, the known measure taken was $3 \mathrm{~cm}$ (Figure 1).

This was used to set the scale as in Figure 2. 
Wound bed is outlined. The Surface area of the marked out area is calculated using the set scale (Figure 3).

Image $\mathrm{J}^{\circledast}$ was used to measure the areas (Figure 4). Serial $6\left(62.007 \mathrm{~cm}^{2}\right)$ is the total surface area of the wound bed. Serial $1-5$ are the areas of the raw areas. Area Serial $1-5$ is totaled $\left(4.148 \mathrm{~cm}^{2}\right)$ and deducted from the total. The Result $\left(57.859 \mathrm{~cm}^{2}\right)$ was calculated as a percentage of the total and that gives the percentage take of Patient 04 on POD 5 calculated using Image $J^{\circledR}$ (93.31\%) (Figure $5)$.

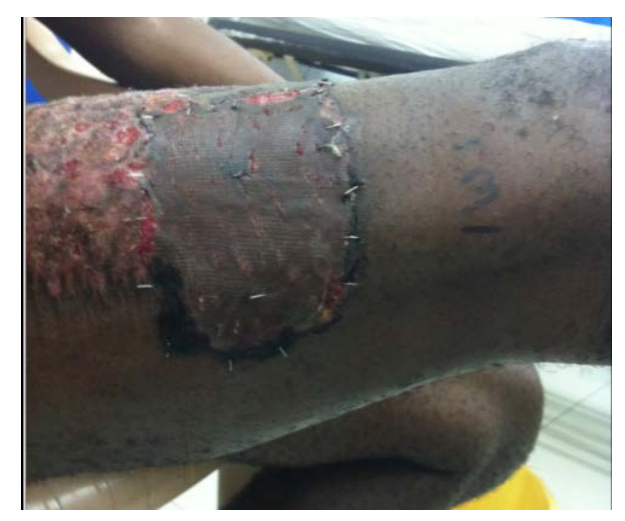

Figure 1. Image of patient 04 on POD 5 with $3 \mathrm{~cm}$ measured on the skin of the patient which was used as the known measure for setting of the scale.

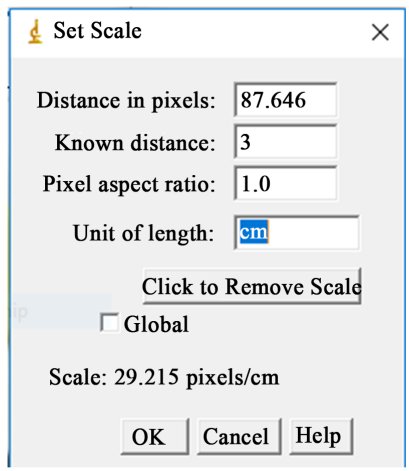

Figure 2. Setting of scale for measurement of patient 04 POD5.

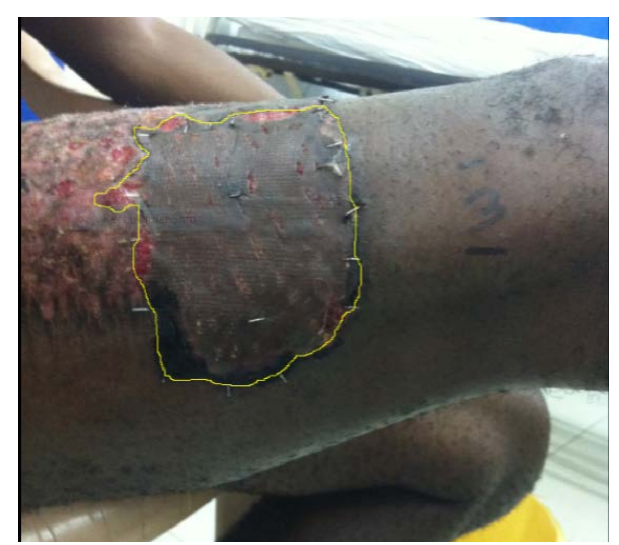

Figure 3. Image of 04 on POD 5 with an outline of the wound to be measured. 


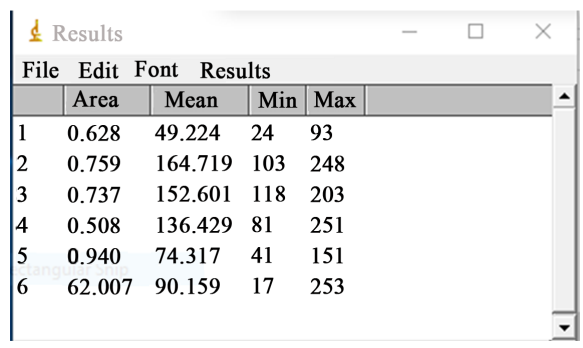

Figure 4. Wound area measurements obtained using Image $\mathrm{J}^{\circledast}$.

\begin{tabular}{|c|c|c|c|c|}
\hline \multicolumn{2}{|l|}{ Graft Take } & Graft Outcome & Successful & $\checkmark$ \\
\hline GT day 5 obs & $98 \%$ & GT day $5 \mathrm{IJ}$ & $93.3 \%$ & \\
\hline GT day 8 obs & $100 \%$ & GT day $8 \mathrm{IJ}$ & $100 \%$ & $\hat{v}$ \\
\hline GT day 14 obs & $100 \%$ & GT day 14 IJ & $100 \%$ & \\
\hline
\end{tabular}

Figure 5. Recorded values of graft take obtained using observation and Image $\mathrm{J}^{\circledR}$ digital imaging for Patient 04 .

\section{Results}

In total, 72 patients were included in the study. The median age of the patients was 30 years (range 3 months to 67 years). Patients aged 18 - 29 years had the highest population forming almost a third of the study population (30.6\%). Men outnumbered women (54.2\% vs 45.8 ). Thirty-one (53.5\%) of the patients above 18 years were found to be obese or overweight.

Table 1 shows the wound aetiologies fell into one of six groups with the majority from trauma and burns i.e. 54 (75\%). The BMI was calculated only for patients 18 years and above (i.e. 57$)$.

\section{Comparison between Estimation of Graft Take, Made by Observation and by Using Image J ${ }^{\circledR}$}

The graft take on Postoperative day 5, Postoperative day 8 and Postoperative Day 14 were recorded using both the Observation and Image J methods (Tables 2-4).

These were compared and statistically analysed. There was no statistically significant difference between the estimation of Graft take, made by observation and using Image $\mathrm{J}^{\circledR}$ digital programme. The only differences were seen with estimates of cellulitic wounds on Day 5 and Flap site wounds on day 14 (Table 5).

\section{Discussion}

Ulcers, including traumatic wounds, defects after resection of tumours, burn wounds, etc., impact negatively on the quality of life. Grafting, which aids faster wound healing, serves as a means to relief the patient of distress. Thus when a graft fails the impact on the patient is immense. Such a patient suffers psychological and financial difficulties, being saddled with the extra cost of another surgery and the extra cost of extended hospital stay. 
Table 1. Demographic and clinical characteristics of study participants.

\begin{tabular}{|c|c|c|}
\hline \multicolumn{2}{|l|}{ Characteristic } & $\begin{array}{c}\text { Proportion } \\
\mathrm{n}, \%\end{array}$ \\
\hline Age range (years) $(\mathrm{N}=72)$ & & $3 / 12-67.0$ \\
\hline Median age [Interquartile Range] (years) $(\mathrm{N}=72)$ & & $30[19-47.5]$ \\
\hline \multirow[t]{6}{*}{ Age group $(\mathrm{N}=72)$} & $<18$ years & $15(20.8)$ \\
\hline & $18-29$ years & $22(30.6)$ \\
\hline & $30-39$ years & $9(12.5)$ \\
\hline & $40-49$ years & $9(12.5)$ \\
\hline & $50-59$ years & $12(16.7)$ \\
\hline & $>59$ years & $5(6.9)$ \\
\hline \multirow[t]{2}{*}{ Gender $(\mathrm{N}=72)$} & Male & $39(54.2)$ \\
\hline & Female & $33(45.8)$ \\
\hline \multirow[t]{2}{*}{ BMI category $(\mathrm{N}=58)$} & Normal & $27(46.5)$ \\
\hline & Overweight/Obese & $31(53.5)$ \\
\hline \multirow[t]{7}{*}{ Ulcer aetiology $(\mathrm{N}=72)$} & Trauma & $28(38.9)$ \\
\hline & Burns & $26(36.1)$ \\
\hline & Cellulitis & $6(8.3)$ \\
\hline & Post ex tumour & $5(6.9)$ \\
\hline & Flap site & $3(4.2)$ \\
\hline & Fasciitis & $2(2.8)$ \\
\hline & SSG donor site & $2(2.8)$ \\
\hline
\end{tabular}

Table 2. Graft take recorded by observation and Image J on postoperative day 5 .

\begin{tabular}{ccc}
\hline Patient Code & GT POD 5 Obs & GT POD 5 IJ \\
\hline 1 & 85 & 71 \\
2 & 99 & 97.5 \\
3 & 98 & 96.7 \\
4 & 98 & 95.8 \\
5 & 85 & 86.1 \\
6 & 90 & 85 \\
7 & 65 & 82.6 \\
8 & 95 & 93.7 \\
9 & 98 & 98.3 \\
10 & 95 & 89.3 \\
11 & 99 & 99.7 \\
12 & 85 & 78 \\
13 & 60 & 87.2 \\
14 & 99 & 98 \\
15 & 95 & 87.1 \\
16 & 85 & 74 \\
17 & 90 & 91.3 \\
\hline & & \\
\hline & & 95 \\
\hline
\end{tabular}




\section{Continued}

\begin{tabular}{|c|c|c|}
\hline 18 & 95 & 88.7 \\
\hline 19 & 90 & 88.2 \\
\hline 20 & 70 & 65.7 \\
\hline 21 & 80 & 66.3 \\
\hline 22 & 100 & 100 \\
\hline 23 & 99 & 97.7 \\
\hline 24 & 90 & 78.8 \\
\hline 25 & 95 & 92.8 \\
\hline 26 & 70 & 76 \\
\hline 27 & 95 & 93 \\
\hline 28 & 99 & 94.7 \\
\hline 29 & 50 & 66.7 \\
\hline 30 & 98 & 97.8 \\
\hline 31 & 85 & 91.6 \\
\hline 32 & 92 & 89.9 \\
\hline 33 & 85 & 82 \\
\hline 34 & 85 & 83 \\
\hline 35 & 95 & 80.8 \\
\hline 36 & 97 & 83 \\
\hline 37 & 92 & 91.4 \\
\hline 38 & 98 & 83.1 \\
\hline 39 & 98 & 96.5 \\
\hline 40 & 95 & 93 \\
\hline 41 & 70 & 84.1 \\
\hline 42 & 100 & 100 \\
\hline 43 & 70 & 61.2 \\
\hline 44 & 75 & 86.2 \\
\hline 45 & 85 & 78.3 \\
\hline 46 & 100 & 100 \\
\hline 47 & 90 & 76 \\
\hline 48 & 80 & 67 \\
\hline 49 & 70 & 83 \\
\hline 50 & 50 & 33.5 \\
\hline 51 & 80 & 74.3 \\
\hline 52 & 100 & 100 \\
\hline 53 & 95 & 86.7 \\
\hline 54 & 80 & 76.7 \\
\hline 55 & 95 & 81.9 \\
\hline 56 & 90 & 88.5 \\
\hline 57 & 85 & 79.8 \\
\hline 58 & 99 & 96.4 \\
\hline
\end{tabular}


K. O. Nsaful et al.

\section{Continued}

\begin{tabular}{lll}
\hline 59 & 95 & 87.9 \\
60 & 85 & 81.3 \\
61 & 98 & 94.1 \\
62 & 80 & 73.3 \\
63 & 90 & 78.1 \\
64 & 85 & 79.1 \\
65 & 98 & 90.1 \\
66 & 95 & 85 \\
67 & 100 & 100 \\
68 & 90 & 83.1 \\
69 & 100 & 97.7 \\
70 & 98 & 97.7 \\
71 & 75 & 81.3 \\
72 & 98 & 93.8 \\
\hline
\end{tabular}

Table 3. Graft take recorded by observation and Image J on postoperative day 8 .

\begin{tabular}{|c|c|c|}
\hline Patient Code & GT POD 8Obs & GT POD 8 IJ \\
\hline 1 & 90 & 76 \\
\hline 2 & 99 & 98.7 \\
\hline 3 & 98 & 90.5 \\
\hline 4 & 100 & 100 \\
\hline 5 & 80 & 75.3 \\
\hline 6 & 80 & 83.2 \\
\hline 7 & 40 & 63.2 \\
\hline 8 & 95 & 98.4 \\
\hline 9 & 90 & 94 \\
\hline 10 & 90 & 88.3 \\
\hline 11 & 95 & 94.6 \\
\hline 12 & 85 & 85.8 \\
\hline 13 & 55 & 68.2 \\
\hline 14 & 98 & 97.6 \\
\hline 15 & 90 & 94.6 \\
\hline 16 & 55 & 66.1 \\
\hline 17 & 98 & 91.6 \\
\hline 18 & 95 & 85 \\
\hline 19 & 60 & 53.7 \\
\hline 20 & 60 & 65.1 \\
\hline 21 & 75 & 62 \\
\hline 22 & 99 & 89.6 \\
\hline 23 & 95 & 89.2 \\
\hline 24 & 90 & 72.3 \\
\hline 25 & 90 & 83 \\
\hline 26 & 60 & 51.3 \\
\hline
\end{tabular}




\section{Continued}

\begin{tabular}{|c|c|c|}
\hline 27 & 85 & 81.7 \\
\hline 28 & 95 & 88.3 \\
\hline 29 & 45 & 66.1 \\
\hline 30 & 85 & 78.5 \\
\hline 31 & 99 & 95.4 \\
\hline 32 & 95 & 83.1 \\
\hline 33 & 85 & 86.5 \\
\hline 34 & 70 & 67.3 \\
\hline 35 & 95 & 71 \\
\hline 36 & 75 & 67.9 \\
\hline 37 & 80 & 89.9 \\
\hline 38 & 80 & 84.6 \\
\hline 39 & 100 & 100 \\
\hline 40 & 100 & 100 \\
\hline 41 & 60 & 81.3 \\
\hline 42 & 98 & 96.4 \\
\hline 43 & 60 & 43.9 \\
\hline 44 & 85 & 88 \\
\hline 45 & 80 & 79.1 \\
\hline 46 & 98 & 98.5 \\
\hline 47 & 85 & 78.5 \\
\hline 48 & 75 & 69.1 \\
\hline 49 & 60 & 81.6 \\
\hline 50 & 30 & 30 \\
\hline 51 & 90 & 78 \\
\hline 52 & 100 & 100 \\
\hline 53 & 80 & 71.8 \\
\hline 54 & 75 & 64.5 \\
\hline 55 & 70 & 74 \\
\hline 56 & 90 & 82.2 \\
\hline 57 & 98 & 94.1 \\
\hline 58 & 65 & 57 \\
\hline 59 & 55 & 62.5 \\
\hline 60 & 80 & 82.5 \\
\hline 61 & 95 & 86.1 \\
\hline 62 & 85 & 79.1 \\
\hline 63 & 92 & 86.3 \\
\hline 64 & 75 & 71.5 \\
\hline 65 & 95 & 89.3 \\
\hline 66 & 90 & 82.5 \\
\hline 67 & 98 & 91.2 \\
\hline 68 & 85 & 79.1 \\
\hline 69 & 95 & 87.3 \\
\hline 70 & 98 & 93 \\
\hline 71 & 80 & 68.3 \\
\hline 72 & 98 & 95.6 \\
\hline
\end{tabular}


K. O. Nsaful et al.

Table 4. Graft take recorded by observation and Image J on postoperative day 14.

\begin{tabular}{|c|c|c|}
\hline Patient Code & GT POD $14 \mathrm{Obs}$ & GT POD 14 IJ \\
\hline 1 & 95 & 83.3 \\
\hline 2 & 100 & 100 \\
\hline 3 & 100 & 100 \\
\hline 4 & 100 & 100 \\
\hline 5 & 80 & 64.1 \\
\hline 6 & 85 & 81.6 \\
\hline 7 & 35 & 41 \\
\hline 8 & 100 & 100 \\
\hline 9 & 90 & 93.6 \\
\hline 10 & 80 & 68.5 \\
\hline 11 & 85 & 90.3 \\
\hline 12 & 80 & 68.7 \\
\hline 13 & 40 & 60.1 \\
\hline 14 & 100 & 100 \\
\hline 15 & 100 & 99.3 \\
\hline 16 & 45 & 31.9 \\
\hline 17 & 98 & 94.6 \\
\hline 18 & 90 & 83 \\
\hline 19 & 40 & 23.9 \\
\hline 20 & 50 & 62 \\
\hline 21 & 35 & 43 \\
\hline 22 & 95 & 90.4 \\
\hline 23 & 90 & 92.1 \\
\hline 24 & 85 & 76.1 \\
\hline 25 & 80 & 77.8 \\
\hline 26 & 60 & 63.2 \\
\hline 27 & 80 & 83.6 \\
\hline 28 & 99 & 93.1 \\
\hline 29 & 45 & 62.1 \\
\hline 30 & 80 & 74.3 \\
\hline 31 & 100 & 100 \\
\hline 32 & 98 & 88.3 \\
\hline 33 & 95 & 88.2 \\
\hline 34 & 85 & 83.6 \\
\hline 35 & 95 & 83.5 \\
\hline 36 & 85 & 79.7 \\
\hline
\end{tabular}




\section{Continued}

\begin{tabular}{|c|c|c|}
\hline 37 & 75 & 87.6 \\
\hline 38 & 90 & 87.6 \\
\hline 39 & 98 & 94.6 \\
\hline 40 & 100 & 100 \\
\hline 41 & 65 & 75.7 \\
\hline 42 & 100 & 98.5 \\
\hline 43 & 40 & 22.7 \\
\hline 44 & 35 & 32.2 \\
\hline 45 & 95 & 87.2 \\
\hline 46 & 98 & 97.3 \\
\hline 47 & 95 & 87.2 \\
\hline 48 & 60 & 62.3 \\
\hline 49 & 40 & 33.9 \\
\hline 50 & 10 & 32.3 \\
\hline 51 & 90 & 82 \\
\hline 52 & 100 & 100 \\
\hline 53 & 90 & 84.9 \\
\hline 54 & 60 & 41 \\
\hline 55 & 20 & 33.7 \\
\hline 56 & 96 & 89.1 \\
\hline 57 & 98 & 92.1 \\
\hline 58 & 10 & 22.7 \\
\hline 59 & 23 & 34.1 \\
\hline 60 & 85 & 87.7 \\
\hline 61 & 95 & 80.8 \\
\hline 62 & 85 & 75.7 \\
\hline 63 & 90 & 87.1 \\
\hline 64 & 95 & 93.1 \\
\hline 65 & 99 & 97.3 \\
\hline 66 & 80 & 71.1 \\
\hline 67 & 85 & 78 \\
\hline 68 & 90 & 81.3 \\
\hline 69 & 85 & 91.4 \\
\hline 70 & 100 & 100 \\
\hline 71 & 95 & 87.1 \\
\hline 72 & 100 & 100 \\
\hline
\end{tabular}


Table 5. Comparison of proportion of ulcer management using observational method and Image $\mathrm{J}^{\circledR}$ method in different ulcer aetiology.

\begin{tabular}{|c|c|c|c|c|c|c|c|c|c|}
\hline \multirow{3}{*}{ Ulcer aetiology } & \multicolumn{3}{|c|}{$D A Y 5$} & \multicolumn{2}{|c|}{$D A Y 8$} & \multicolumn{4}{|c|}{$D A Y 14$} \\
\hline & Observation & Image $J$ & \multirow{2}{*}{$p$-value } & Observation & Image J & \multirow{2}{*}{$p$-value } & Observation & Image J & \multirow{2}{*}{$p$-value } \\
\hline & mean $\pm S D$ & mean $\pm S D$ & & mean $\pm S D$ & mean $\pm S D$ & & mean $\pm S D$ & mean $\pm S D$ & \\
\hline Trauma $(\mathrm{n}=28)$ & $92.35 \pm 10.64$ & $90.44 \pm 8.84$ & 0.114 & $90.32 \pm 12.88$ & $88.21 \pm 9.44$ & 0.135 & $86.14 \pm 19.84$ & $84.04 \pm 18.04$ & 0.114 \\
\hline Burns $(n=26)$ & $83.50 \pm 11.14$ & $81.75 \pm 8.78$ & 0.399 & $77.42 \pm 15.33$ & $74.55 \pm 10.87$ & 0.215 & $74.77 \pm 22.83$ & $72.54 \pm 20.81$ & 0.224 \\
\hline Cellulitis $(n=6)$ & $95.17 \pm 3.54$ & $88.10 \pm 8.23$ & 0.047 & $77.88 \pm 9.91$ & $75.60 \pm 12.13$ & 0.493 & $60.00 \pm 35.36$ & $64.18 \pm 28.51$ & 0.340 \\
\hline Post ex tumour $(n=5)$ & $92.80 \pm 7.36$ & $90.12 \pm 10.44$ & 0.281 & $86.40 \pm 19.40$ & $87.30 \pm 15.55$ & 0.754 & $85.00 \pm 23.97$ & $78.90 \pm 30.42$ & 0.154 \\
\hline Flap site $(n=3)$ & $90.00 \pm 5.00$ & $84.50 \pm 5.44$ & 0.116 & $83.33 \pm 5.77$ & $77.70 \pm 5.34$ & 0.141 & $93.67 \pm 3.21$ & $87.07 \pm 2.10$ & 0.014 \\
\hline Fascitis $(\mathrm{n}=2)$ & $60.00 \pm 14.14$ & $47.35 \pm 19.59$ & 0.188 & $45.00 \pm 21.21$ & $36.95 \pm 9.83$ & 0.500 & $25.00 \pm 21.21$ & $27.50 \pm 6.79$ & 0.920 \\
\hline
\end{tabular}

A variety of factors are believed to adversely influence skin graft take; haematoma, shearing movements [12], inadequate compliance, deficient blood supply [13], are examples. Infection is the second most frequent cause of Skin graft loss [14].

The percentage graft take, noted and documented, often goes a long way to influence management plans of whether to continue with wound dressing or to re-graft the wound. Therefore, the take of the skin graft, traditionally estimated by observation needs to be as precise as possible and dependable.

In this study, there was no significant difference between the estimation of graft take, made by observation and estimation made using Image ${ }^{\circledast}$ digital programme. The fact that the residents who were estimating the graft take by observation, were blinded to the results by the Image J, removed biases and influences. Thus it can be said that the practice of estimating graft take by observation as done at NRPSBC is acceptable.

In this study, the estimation by observation was made by senior residents in plastic surgery. Therefore it can be said that in as much as the method of estimation by observation was found to be reliable, this reliability depended on the experience of the persons making the estimation.

\section{Conclusion}

Graft take ideally must be made by an objective method such as an image analyzer. However the method of estimation of graft take by observation is an acceptable practice and can be relied upon to make decisions on patient management.

\section{Author Contribution}

All authors have contributed to all process in this research, including preparation, data gathering and analysis, drafting and approval for publication of this manuscript. 


\section{Conflicts of Interest}

This was a secondary finding in work (Evaluation of bacterial infection of split-thickness skin grafts at the Korle Bu Teaching Hospital) which was presented as a dissertation submitted to the Faculty of Surgery of the WEST AFRICAN COLLEGE OF SURGEONS in part-fulfilment of the requirements for the award of the Final Fellowship of the West African College of Surgeons (FWACS) in Plastic Surgery in October 2017. Financial Assistance was sort for and received from the Management of the National Reconstructive Plastic Surgery and Burns Centre of the Korle Bu Teaching Hospital.

\section{References}

[1] Andreassi, A., Bilenchi, R., Biagioli, M. and D’Aniello, C. (2005) Classification and Pathophysiology of Skin Grafts. Clinics in Dermatology, 23, 332-337. https://doi.org/10.1016/j.clindermatol.2004.07.024

[2] Ratner, D. (1998) Skin Grafting: From Here to There. Dermatologic Clinics, 16, 75-90. https://doi.org/10.1016/S0733-8635(05)70488-5

[3] http://practicalplasticsurgery.org/docs/Practical_12.pdf

[4] Valencia, I.C., Falabella, A.F. and Eaglstein, W.H. (2000) Skin Grafting. Dermatologic Clinics, 18, 521-532. https://doi.org/10.1016/S0733-8635(05)70199-6

[5] Mutalik, S. and Ginzburg, A. (2000) Surgical Management of Stable Vitiligo: A Review with Personal Experience. Dermatologic Surgery, 26, 248-254. https://doi.org/10.1046/j.1524-4725.2000.09182.x

[6] Schneider, C.A., Rasband, W.S. and Eliceiri, K.W. (2012) NIH Image to ImageJ: 25 Years of Image Analysis. Nature Methods, 9, 671-675. https://doi.org/10.1038/nmeth.2089

[7] Abramoff, M., Magalhaes, P. and Ram, S. (2004) Image Processing with ImageJ. Biophotonics International, 11, 36-42.

[8] Collins, T.J. (2007) ImageJ for Microscopy. Biotechniques, 43, 25-30. https://doi.org/10.2144/000112517

[9] Girish, V. and Vijayalakshmi, A. (2004) Affordable Image Analysis Using NIH Image/ImageJ. Indian Journal of Cancer, 41, 47.

[10] https://imagej.nih.gov/ij/docs/menus/analyze.html

[11] Zekri, A. and King, W. (1995) Success of Skin Grafting on a Contaminated Recipient Surface. European Journal of Plastic Surgery, 18, 40-42. https://doi.org/10.1007/BF00183697

[12] McGregor, A. and McGregor, I. (2000) Free Skin Grafts. In: Fundamental Techniques of Plastic Surgery, Churchill Livingstone, Edinburgh, 35-59. https://doi.org/10.1016/B978-0-443-06372-5.50007-3

[13] Browse, N.L., Gray, L., Jarrett, P.E. and Morland, M. (1977) Blood and Vein-Wall Fibrinolytic Activity in Health and Vascular Disease. British Medical Journal, 1, 478-481. https://doi.org/10.1136/bmj.1.6059.478

[14] Thornton, J. and Gosman, A. (2004) Selected Readings in Plastic Surgery. Vol. 10, Selected Readings in Plastic Surgery, Inc., Dallas. 